\title{
The Management of a Plastic Instrument The way from idea to patent and final product
}

\author{
STEFAN LUCIAN BURLEA ${ }^{1}$, ANAMARIA CIUBARA ${ }^{2 *}$, GEORGETA BURLEA ${ }^{3}$, RAMONA CIMPOESU ${ }^{4}$, \\ ${ }^{1}$ Grigore T. Popa University of Medicine and Pharmacy, 16 University Str., 700115, Iasi, Romania \\ 2 Dunarea de J os University of Galati, Faculty of Medicine and Pharmacy, Department of Psychiatry, 47 Domenasca Str., \\ 800008, Galai, Romania \\ ${ }^{3}$ Sfanta Maria Pediatric Hospital, 62 Vasile Lupu Str., 700309, Iasi, Romania \\ ${ }^{4}$ Gheorghe Asachi Technical University of Iasi, 59A Dimitrie Mangeron Str., 700050, lasi, Romania
}

\begin{abstract}
The article presents the procurance of an apparatus intended for the stage of reading and writing, used both by the pre-school children and the persons who present speaking deficiencies, obtained from plastic parts marked and processed using a laser equipment. The learning equipment of writing and reading consists in a carcass of a triangular prism which has on a lateral side two visualization windows and a magnetic plate for writing, placed one below the other, atan appropriate distance, each visualization window being equipped with several illumination sources, disposed in a lineal way along the window, having an independent performance.
\end{abstract}

Keywords: equipment management, plastic elements, read/write equipment, laser

From the patent RO 94948, it is known a didactic apparatus in order to learn letters and words forming, constituted from a box with alveolus, in the right side being printed signs and letters, which can be found inscribed on cards deposited in the appropriate alveolus of the box, a table for the placement the adequate cards in order to form the words [1].

From the patent RO 89979 it is also known a programmable device of learning for the persons with speaking deficiencies, device constituted from resonant sources, radiators, acoustics and commutants, a programming unit and a delaying unit, a mixer amplifier connected to the external resonant sources, the entering of the programming unit being connected at the exit of a commuting unit at which are spliced resonant sources [2].

Using this complex device it is expected the improvement through repeated practice of the speaking deficiency, as in the case of stammering. The patent RO 120992 provides information about a didactic device for learning reading and writing, where with the aid of the words these are constituted from separate letters of the alphabet, letters that are inscribed on some discs of decreasing diameters disposed concentrically in sectors which dispose the circumferences of the discs. In a parallelipipedic body, the discs are attached on a common ax, having the possibility of circumrotate around this ax. [3]. Opaque cursors obstruct partially some of the letters so as the letters that compound the word can be visualized through a window made on the upper surface of the parallelipipedic body. The document RO 118684 refers to a didactic device, constituted from a parallelipipedic body, provided with a visualization window and some opaque cursors which can move by gliding, obstructing totally or partially the visualization window. In the parallelipipedic carcass are fitted on a central piece a set of superposed discs, concentrically, with decreasing diameters on which are inscribed the letters of the al phabet and between each disc and the central piece are placed labeling mechanisms, which stop the discs, bonding in predetermined positions [4-6].

These devices for speaking and reading learning are quite difficult to handle, they do not allow the correlation of the word forms with a correct visualization of the graphic representation of the specific word, being also possible the formation of wrong words, through erroneous choice of the letters or the formation of the letter combination can be difficult and unattractive for the pre -school children [7]. The technical problem that is solved through the present invention consists in getting together in a single device both the visualization function of a letter or a word, and the graphic representation of the signification of the formed word and the possibility of writing the letters of a word on a table incorporated in this apparatus, the visual perception of the image of letter or word being correlated with the auditory perception of the phonemes [8-10].

In this article it is presented the proposition of an equipment for the learning stage of the writing-reading process, constituted from a carcass with the shape of triangular prism which has processed on one of the lateral side two windows of visualization and a magnetic plate for writing, disposed one below the other, at an appropriate distance, each visualization window being provided with several sources of illumination, disposed in a line along the window, having an independent performance.

\section{Experimental part}

Inside the carcass of the equipment there are assembled coils of winding and unwinding and coils of support for an endless band, inscribed linearly with several graphic representations, together with the denominations of those, images that can be visualized through the upper window and that can be obstructed with the help of a gliding horizontal cursor. In the lower window can be visualized the letters of the alphabet, signs of punctuation or numbers. These elements are inscribed on the lateral surfaces of some discs that are placed one beside the other. These discs are assembled on a horizontal ax parallel with the coil that allows the visualization of the coil with images in the upper window, under the second window of visualization, having a magnetic rectangle plate for the writing of the letters or the formed word visualized by the user. In order to handle easily the apparatus and to stabilize it, on a plain surface on the sides of the carcass there are placed handles and at the bottom rubber legs. 


\section{Experimental part}

Following, we give an example of building the readingwriting learning device according with the sketches presented in figure $1 a$ and $b$.

The apparatus for the stage of learning reading and writing, according to the proposal, is made of a carcass, figure 1, having the shape of a triangular prism which has processed on one of the lateral sides two visualization windows, 2 and 2 ', that are placed one below the other at an adequate distance. The upper window 2 is provided with several sources of illumination 3, which are placed collinearly along the window 2, inside the carcass 1 . Each of these has an independent performance, being sourced from a battery that is not represented in the carcass 1 . Parallel with the upper window 2, it is uncoiled a continuous band 4, which has inscribed collinearly the letters of the alphabet, signs and figures that can be visualized through the window. On the coil 4, parallel with each letter it is inscribed a word that begins with the respective letter, together with the graphical representation of the signification of the word, for example: for the letter $\mathrm{N}$ the word needle and the graphic representation of a needle. The letters, words and the graphic representation are grouped, disposed collinearly and correlated with the letter represented on the width of the coil 4 . The band is endless and it can be rolled inside carcass 1 on winding coils 5 , also on unwinding coils 6 , having an own system of sustaining and stretching, made of support coils 7 , the disposal of these coils being made after a known system. Driving, respectively the winding of the band 4 is performed with the help of a rosette 8 , disposed on one of the lateral sides of the carcass 1.

The letters, words which begin with certain letters and the graphic representations of these words, inscribed on band 4 , can be illuminated individually due to the light sources 3 , which present a lighting contact 9 , individually disposed above the upper window 2 , on the surface of the carcass. In this way, each of the letters that is learned can be perceived visually and noticed through light by the user of the device or by the speech therapist.

The upper window 2 has shaped on the upper and lower edge longitudinal canals, that allow the horizontal gliding

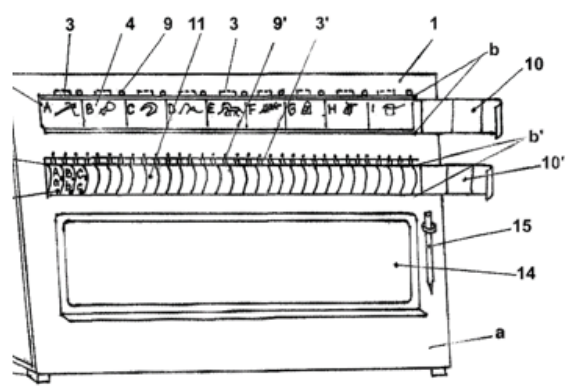

a)

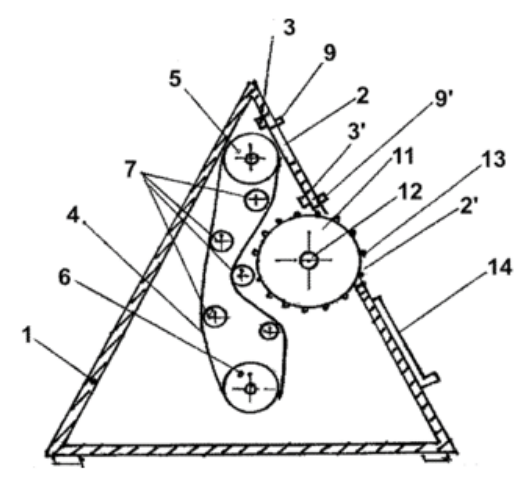

b) of some cursors 10 . Through the individual gliding movement of one or more of the cursors 10 , some of the letters represented, the specific word and the graphic representation of this that are inscribed on band 4 , can be obstructed depending of the desire and feature of the exercise.

Under the upper window 2, it is shaped a second visualization window, namely the lower window 2', fact that allows the visualization both the major or minor letters of the alphabet, the hand written letters and the signs of punctuation. These letters in differentformats are inscribed on the lateral and circumference surface, of some discs 11 that are assembled one near other on a horizontal ax 12 , which is disposed in the carcass 1, parallel with the coil 5 , on which is enveloped the band 4 with images. Each disc 11 has inscribed on the circumference, one under another, the letters of the alphabet, signs of punctuation and free spaces.

Next to each letter on the circumference of the disc 11,there are fitted cotters 13 which allow a smooth rotation of the discs 11, permitting also the selection of the chosen letter in the visualization window 2'. As well as the visualization window 2 , the lower window is fitted with individual sources of light 3 ', for each of the discs 11, sources that are driven through a lighting contact 9', individually for each of the discs. The visualization window 2 ' is fitted with longitudinal canals $b$ ' that permit the horizontal gliding of the cursors $10^{\prime}$. Through the individual gliding movement of one or many cursors 10', some of the letters inscribed on the circumference of the discs 11 can be obstructed, depending of the character of the exercise.

Under the visualization window 2 ' it is placed a magnetic rectangular plate 14 and a pen 15 in order to write the letter or the word formed or visualized bythe user. To handle easily the device, but also for the stabilization of the apparatus, on the lateral surfaces of the carcass 1 , there are fitted rubber legs 17. The apparatus can work charged with electric current or with batteries.

In order to form a lexical inventory, adapted to the age or the needs of the users, and also for the study of a foreign language, the band 4 can be imprinted too with other graphic representations, written in the desired language.

In order to learn the major and minor letters of the alphabet, the discs 11 can have inscribed the desired size of the letters. Changing these, depending the destination is possible due to the band 4 or the discs 11 on the horizontal ax 12. This is possible due to the lateral cap 18 of the carcass 1.

The letters inscribed on the discs 11 and phonetically speaking are consonants are inscribed with a certain color and the letters that represent vowels are inscribed with a different color.

The apparatus for the stage of learning reading and writing, according to the proposal of the device presented in the article can be used either individually or in the presence of a speech therapist enhancing the stimulation of an accurate speech, the recognition of the letters of the alphabet and the right formation of words or splitting into syllables the words.

On the other hand, the user understands better the importance of the place of a letter or sound in a structure, highlighting the combinatory variety of letters, sounds and the graphical representation of the formed words.

\section{Conclusions}

In this article we propose the execution of an apparatus from plastic elements processed with a laser equipment for the reading-w riting stage, characterized by the fact that 
each disc is inscribed on the circumference with the letters of the alphabet, signs of punctuation and a gap. Next to each letter on the circumference surface there are beaks that permitan easy rotation of the discs and the attachment of the desired letter in the visualization window.

The advantages of the experimental device consist in : the upper part of the device allows the focus of attention on the highlighted image; the visual perception of the image and the word connected with their denomination; the auditive perception of the forms concomitant with the visual perception of the letters; the selection of the letters in order to form syllables and words from letters; easy and attractive manoeuvrability for children; the possibility for the users to build a flexible and creative process of thinking and finally the development of a lexical active stock.

Authors' contribution: Stefan Lucian BURLEA made the conversion from idea to patent for this experimental equipment. Anamaria CIUBARA realize the main elements analyse for this product, the connections between the equipment elements and the impact on the society of this product. Georgeta BURLEA, was the expert in speech and language of children development. Ramona CIMPOESU participate through identification of the best plastic materials solutions for this equipment in order to fulfil the strength resistance and the weight of the equipment.

\section{References}

1.*** RO 125059 B1, http://pub.osim.ro/publication-server/pdfdocument?P N=R0125059\%20R0\%20125059\&iDocld = 4606\&ie patch $=$.pdf.

2. PAUN, V.P., CIMPOESU, N., CIMPOESU, R., MUNCELEANU, G.V., FORNA, N., AGOP, M., Mat. Plast., 47, no. 2 , 2010, p. 158

3.BELDESCU, G., TURCULET, A. Introducere în fonetica limbii romane, Iasi, 2000

4.CASALIS, S., Reeducation orthophonique, nr. 204, 2000, p. 19-35

5.DANAILA, L., GOLU, M. Tratat de neuropsihologie, vol. I, Ed. Medicala, Bucuresti, 2002

6.ENACHESCU, C., Neuropsihologie, Editura Victor, Bucuresti, 1996 7.GOGA, M. Limba romana. Fonetica si fonologie. Lexicologie. Stilistica, Editura Limes, Cluj Napoca, 2001

8.PERFETTI, C.A. Representation et prise de conscience au cours de l'apprentissage de la lecture. In L'apprentilecteur, Editura DelachauxNiestle, Neuchatel - Lausanne, pg. 103-128, 1989.

9. PAUN, M.A., CIMPOESU, HANU, R., CIMPOESU,N., AGOP, M., BACIU, C., STRATULAT, S., NEJ NERU, C., Mat. Plast., 47, no. 2 , 2010, p. 209 10.VERZA E., Tratat de logopedie, Editura Fundapiei Humanitas, Bucuresti, 2003

Manuscript received: 11.10 .2016 